\title{
Social and competitive threat as situational factors moderating relationships between moral judgments and different components of authoritarian ideology
}

\author{
Piotr Radkiewicz ${ }^{1}$ (D) \\ Accepted: 17 September 2020 / Published online: 29 September 2020 \\ (C) The Author(s) 2020
}

\begin{abstract}
This paper presents research on the complexity of moral judgments underlying two components of authoritarian ideology: rightwing authoritarianism (RWA) and social dominance orientation (SDO). Based on previous research, it was expected that people who were high on moral intuitions of Ingroup/loyalty and Authority/respect (Ethics of Community) should be high on RWA, whereas people who were high on moral intuitions of Care/harm and Fairness/reciprocity (Ethics of Autonomy) should be low on SDO. In more detailed hypotheses it was assumed that such general relationships would be moderated by situational factors threat to social order and competitive threat, respectively. Two experimental studies were conducted: the first with manipulation of the threat to social order, and the second with manipulation of the competitive threat ( $N=180$ and 150 , respectively). Both studies showed that Ethics of Community predicted clear increase in RWA, while the Ethics of Autonomy predicted considerable decrease in SDO. However positive relationships between Ingroup/loyalty and RWA as well as between Authority/respect and RWA were strongly reinforced by threat to social order, whereas the negative relationships between Care/harm and SDO as well as between Fairness/reciprocity and SDO diminished under situationally induced aggressive 'Darwinian' competition. The Ethics of Community appears as a moral basis for development of right-wing authoritarianism, and this relationship is especially strong when the social order is perceived as threatened. On the other hand, the Ethics of Autonomy can be seen as a moral basis for inhibition of social dominance orientation, but it loses the moral relevance in strongly competitive social environment.
\end{abstract}

Keywords Moral intuitions · Authoritarianism $\cdot$ Social dominance orientation $\cdot$ Social threat

Morality is pointed out by many researchers as a powerful source of human motivation (e.g. Kohlberg 1969; Gilligan 1982; Turiel 1983; Haidt and Joseph 2007). It is also indisputable that the domain of moral judgments is inseparable from worldview orientations, i.e. relatively stable sets of beliefs and judgments about the surrounding world. Worldview orientations make holistic, often very complex narratives that organize and structure various aspects of human existence, including issues such as human nature, meaning of life, place of an individual in the social community, etc. They are reflected in varied hierarchies of values and goals adopted by people.

Electronic supplementary material The online version of this article (https://doi.org/10.1007/s12144-020-01075-7) contains supplementary material, which is available to authorized users.

Piotr Radkiewicz

pradkiewicz@psych.pan.pl

1 Institute of Psychology, Polish Academy of Sciences, Jaracza 1 str, 00-378 Warsaw, Poland
A new research perspective linking moral judgments and worldview orientations was opened by the theoretical approach which posits a descriptive and naturalistic view on morality. It comes from the work of Shweder et al. (1997), who argued for the cultural universality of three ethical codes: individual autonomy (protection of individual rights), community (protection of group rights), and divinity. This approach was subsequently developed in the form of Moral Foundations Theory (MFT) (Haidt and Joseph 2007; Graham et al. 2009; Graham et al. 2011). MFT explains the origins of human moral reasoning on the basis of innate, modular foundations and emphasizes the central role of automatic affective evaluations (moral intuitions) in making moral judgments. There are five modular foundations underlying human moral reasoning: Care, Fairness, Loyalty, Authority, and Purity (Haidt and Joseph 2007; Graham et al. 2009). In this approach, Care/harm and Fairness/reciprocity on the one hand, and Ingroup/loyalty and Authority/respect on the other, make up what Shweder et al. (1997) called the Ethics of Autonomy (EA) and Ethics of Community (EC), respectively. 
The Ethics of Autonomy functions to protect individuals and uses concepts such as harm, suffering, rights, and justice. Such moral judgments are based on respect for good, freedom and the rights of a human being, helping others, and loyalty to individuals. On the other hand, people also believe that there are collective entities worth protecting besides individuals. Therefore, the Ethics of Community functions to protect groups, institutions, and other collective entities. These moral judgments are based on loyalty to a group, duty, honor, respect, self-control, obedience, authority, and activities consistent with the ascribed social roles.

What people consider good or bad, commendable or worthy of condemnation, seems to be the natural and basic premise for building a coherent ideological vision of the social order contained in different worldview orientations. One of them is authoritarianism - a classic construct described in Adorno et al. 1950 by Adorno and colleagues as authoritarian personality (Adorno et al. 1950). This construct has undergone numerous revisions and the Dual-Process Motivational (DPM) model (Duckitt 2001; Duckitt et al. 2002; Duckitt and Sibley 2010) can be considered the most influential one today. In the DPM model authoritarianism is more ideological than personality characteristic, and includes two separate constructs: right-wing authoritarianism (RWA) (Altemeyer 1981; Altemeyer 1996) and social dominance orientation (SDO) (Pratto et al. 1994; Sidanius and Pratto 1999). As considered together, RWA and SDO combines two components of the classic construct - 'submissive' and 'dominative'. Right-wing authoritarianism plays a role of 'submissive' authoritarianism - a form of ideology which expresses: a) thoughtless submission of an individual to in-group norms; b) aggression as a general hostility towards people who do not respect the norms and rules established by socially legitimized authorities; and c) conventionalism of the social behavior based on standards and practices established by such authorities. On the other hand, social dominance orientation functions as 'dominative' authoritarianism - a form of ideology that promotes a specific type of social relations between the in-group and out-group, based on hierarchy and domination.

According to DPM model, the duality of human motivation underlying RWA and SDO comes from two deep human misgivings: fear of societal disintegration and fear for survival in a society where homo homini lupus, respectively. Both RWA and SDO, just like in the classic approach (Adorno et al. 1950), have many similar social consequences (e.g. Pratto et al. 1994; Altemeyer 2004; Duriez et al. 2005; McFarland 2010; Duckitt and Sibley 2010) but they also have different personality and motivational origins (Duckitt and Sibley 2010). Moreover, although in most of the national samples RWA and SDO are linked by a clear positive correlation, there are also such countries (Central and Eastern Europe) in which this correlation is non-significant or even slightly negative (Duriez et al. 2005; Radkiewicz 2016).
The Moral Duality of Authoritarian Ideology

Based on the empirical evidences, many researchers (e.g. Schwartz 1994; Saucier 2000; Ashton et al. 2005; Duckitt and Sibley 2010) argue that socio-cultural attitudes, orientations and values form two superordinate and roughly orthogonal dimensions, which have their specific, inexhaustible potential to generate coherent sets of socio-political attitudes (ideologies). The extremes of the first dimension are comprised of 'liberal' characteristics on the one hand, and 'anti-liberal' characteristics on the other hand; the extremes of the second one are determined by 'egalitarian' vs 'anti-egalitarian' characteristics. Studies on the DPM model suggest that RWA and SDO (especially in terms of predictive power) can be described as representing the core of anti-liberal and anti-egalitarian attitudes, respectively (Duckitt 2001; Duckitt et al. 2002; Duckitt and Sibley 2010). In recent years, quite numerous studies showed that such ideological duality corresponds with the duality of moral judgments. In Graham et al. (2009) studies liberals consistently showed greater endorsement and use of EA foundations (harm/care and fairness/reciprocity) compared to EC foundations (ingroup/loyalty and authority/ respect), whereas conservatives endorsed and used all of the foundations more equally. Kugler et al. (2014) and Radkiewicz (2016) showed RWA to be positively related to Ingroup/loyalty and Authority/respect, whereas SDO turned out to be negatively related to Harm/care and Fairness/reciprocity.

Research suggest moral dualism of the authoritarian ideology. The virtues of the Ethics of Community (related to ingroup loyalty and respect for authority) clearly corresponds with the ideological content of submissive authoritarianism (RWA). They strengthen harmony and cohesion of a community, but to a large extent at the expense of individual rights and freedoms. And this is often against the democratic principles of freedom, human rights and tolerance (liberal values). On the other hand, the virtues of the Ethics of Autonomy (Care/harm and Fairness/reciprocity) are in clear contradiction to the ideological content of dominative authoritarianism (SDO). They work for harmonious and cohesive social relations. And this is usually supporting for the democratic principles of equality and social solidarity (egalitarian values). Finally, it is worth noting that in the mentioned studies the moral foundation of Purity/sanctity considerably correlates with the virtues of the Ethics of Community, as well as with conservative ideology contained in RWA. This is because both, EC and RWA, usually go hand in hand with religious beliefs, which largely builds on the moral premises of Purity/sanctity.

The above reasoning assumes that intensity and specific configuration of moral intuitions influence the approval of 
authoritarian ideology. In the theoretical perspective developed by Shweder and Haidt, moral intuitions are recognized as the result of innate and automatic affective processes. Therefore, they are treated as fairly strong and relatively stable dispositions, which can be a natural basis for development or adopting various socio-political ideologies. However, it is necessary to point out that the issue of causality in the relationships linking morality and authoritarianism can be seen as problematic. Indeed, some authors argue for the reverse direction of causality (Kugler et al. 2014), and we believe that it is reasonable, because mutual relationships between morality and authoritarianism should be bidirectional. Even if we assume that morality is a natural, psychobiologically conditioned determinant of the ideological orientations like authoritarianism (Graham et al. 2009), such worldview orientations (as the source of various socio-political beliefs and attitudes) become the basis for justifying one's own behavior and therefore should reinforce moral intuitions. Consequently, assumption as to causality mainly depends on the research problem raised by the researchers.

\section{The Current Research}

As shown by international comparative studies (e.g. results of the International Social Survey Programme in 1995, 2003 and 2013), the approval for authoritarian ideology is characterized by high dynamics - it can distinctly increase or decrease. Recently, researchers point to a significant increase in authoritarianism in many European Union countries (e.g. Fukuyama 2018; Kreuden-Sonnen 2018). At the same time, reports developed on the basis of Eurobarometer studies show a clear decline in satisfaction with democracy (Standard Eurobarometer 88 2017).

Many researchers argue that such fluctuations are closely related to the occurrence of factors inducing a sense of danger and uncertainty (e.g. mass immigration, financial crisis, rising unemployment). Sociologists and social psychologists have repeatedly shown the rise of right-wing authoritarianism or group-based dominance in societies experiencing chaos and disintegration (e.g. Altemeyer 1996; Stellmacher and Petzel 2005; Bell 1996). In the broadly discussed work of Jost et al. (2003), the authors look at anti-liberal and anti-egalitarian ideology as a product of socio-cognitive motives (epistemic, existential, and ideological) powered by such environmental stimuli as fear, threat, or uncertainty.

Similar conclusions can be drawn from research carried out in the theoretical framework of the Dual-Process Motivational model. This approach highlights two types of situational factors that can characterize an individual's social environment and induce a sense of danger and uncertainty: 1) the experience of threat to social order which deprives people of basic control over their own life (reflected in individual's cognitive structures as the Dangerous World Belief); and 2) the experience of 'social jungle', i.e. living in the social environment full of ruthless struggle and competition, where power and money rule over social relations, and cool, cynical manipulation is accepted as an effective way of achieving one's own goals (reflected in individual's cognitive structures as the Competitive Jungle Belief). Referring to the results of experimental studies, Duckitt and Sibley (2016) argue that social threat to societal stability, order and cohesion increases RWA. This has been demonstrated in two experiments in which the researchers verified whether social threat to stability and order would affect RWA and not SDO (Duckitt and Fisher 2003; Jugert and Duckitt 2009). Social threat was manipulated by having participants read a hypothetical scenario depicting dangerous and threatening future for their country, and researchers found that this indeed increase RWA. Similar effects were found in scenario-based experiments by Altemeyer (1988) who asked participants to read about destabilizing political crisis in their society, as well as in experiments in which terrorist threats were made salient for participants (Fisher et al. 2010; Asbrock and Fritsche 2013). On the other hand, Duckitt and Sibley (2016) refer to experimental research in which competitively based groups increase SDO. Several studies showed that this occurred when the social or group context involved competitiveness from or toward other groups (competitive threat) (Morrison and Ybarra 2008; de Oliveira et al. 2012).

Results showing the growth of RWA and SDO under the influence of social/ competitive threat have become the starting point for the current research. We focused on the question of what is happening with relationships linking moral intuitions and authoritarian ideology in times of growing threat. This issue has not been investigated so far, and we think that such investigation can be an important contribution to understanding the social consequences of authoritarian ideology. Especially in the context of reasons why RWA and SDO have become so intensely studied psychosocial variables. Numerous research show that authoritarianism is a strong determinant of social intolerance, discrimination, inter-group hostility, prejudices, etc. (e.g. Pratto et al. 1994; Sidanius and Pratto 1999; McFarland 2010; Duckitt and Sibley 2010). When authoritarianism grows, the level of such in-group and out-group phenomena inevitably increases. Perhaps because they become morally irrelevant, or perhaps they become easier to accept in moral terms?

Attenuation or disappearance of the relationships between moral intuitions and authoritarianism would mean that faith in authoritarian ideology loses its moral grounds. People may become anomic and the potential increase in authoritarianism could be interpreted as the reaction to normative disorientation. On the other hand, reinforcement or consolidation of the 
relationships between morality and authoritarianism would mean that the tendency to authoritarian thinking and behavior undergoes a strong moralization. In this case, authoritarian ideology becomes an instrument of 'the struggle between good and evil' which takes place on the basis of moral principles.

According to the DPM model social threat activates the motivational goal of establishing and maintaining collective security, order, cohesion, and stability. This finds expression in high RWA. A number of experimental studies suggest that exposure to social threat causes an increase in RWA, but not in SDO (e.g. Fisher et al. 2010; Asbrock and Fritsche 2013). One can suppose that the context of social threat may also have a specific effect on the relationship between Ethics of Community and RWA. Based on earlier studies (e.g. Kugler et al. 2014; Radkiewicz 2016), we know that people who are high on EC, are expected to be relatively high on RWA. However, this tendency should be especially strong when the social order is perceived as breaking down. In such a situation the moral virtues of respect for authority, obedience and loyalty to the group are fully in line with the motivational goals included in RWA ideology offering social control and security. At moments of perceived threat to social order, the Ethics of Community should be important justification for stronger RWA expression, in particular for people with a relatively high level of EC. Especially for such people RWA ideology will be seen as an effective way to restore social order and to ensure personal safety.

Summarizing, exposure to the threat of social order may cause an increase in RWA, but it is also expected to be the moderator of the positive relationship between moral intuitions of the Ethics of Community and right-wing authoritarianism. The above argumentation suggests the following hypotheses about moderation effect:

$\mathrm{H}_{1}$ : the strongest positive relationship between Ingroup/ loyalty and RWA as well as between Authority/respect and RWA should be observed when the social order is perceived as threatened.

On the other hand, the DPM model predicts that environment organized on the principles of 'social jungle' activates the value or motivational goal of power, dominance, and superiority, which is expressed in high SDO. Experimental studies suggest that exposure to competitive threat causes an increase in SDO (Morrison and Ybarra 2008; de Oliveira et al. 2012). We suppose that the context of competitive threat may also have a specific effect on the relationship between Ethics of Autonomy and SDO. Based on earlier studies (e.g. Kugler et al. 2014; Radkiewicz 2016), we know that people who are high on EA are expected to be relatively low on SDO. High level of EA seems to be efficient remedy against the ideology of social dominance and injustice. The similar logic as the one applied to $\mathrm{H}_{1}$ makes us expect that the negative relationship between the Ethics of Autonomy and SDO will be the strongest, when the social context of aggressive and ruthless competition is activated. At moments of perceived competitive threat, we can expect increase in SDO especially in people with a relatively low Ethics of Autonomy, i.e. with a low level of moral virtues related to care for others, justice, and reciprocity. It's mainly for these people SDO ideology should be the most accurate rule of conduct in social interactions.

Summarizing, exposure to the competitive threat may cause an increase in SDO, but it is also expected to be the moderator of the negative relationship between moral intuitions of the Ethics of Autonomy and social dominance orientation. The above argumentation suggests the following hypotheses about moderation effect:

$\mathrm{H}_{2}$ : the strongest negative relationship between Care/ harm and SDO as well as between Fairness/reciprocity and SDO should be observed when the social environment is perceived as governed by the rules of aggressive and ruthless competition.

\section{Materials and Methods}

\section{Study 1}

\section{Manipulation and Pilot Study}

Three scenarios were prepared. Their content was partly derived from the research of Duckitt and Fisher (2003). Participants were asked to imagine themselves in 10 years, in specific scenarios. In that imagined future their personal life situation was positive and consistent with their expectations, whereas the social and political conditions in the country differed thoroughly depending on the scenario. In Group 1 (neutral), the socio-political reality was very similar to the current one. In Group 2 (secure), the socio-political conditions have changed significantly for the better thanks to the stable and harmonious development of the country, accompanied by very high economic growth. In Group 3 (threatened), the socio-political conditions have deteriorated dramatically due to an economic crisis, a huge increase in crime, political conflicts, etc. The full text of the three group scenarios is provided in the supplementary materials.

The effectiveness of manipulation procedure was first checked in a pilot study on 150 volunteers randomly assigned to three equal groups. After reading the scenario, respondents were asked to respond to a set of 10 balanced items selected from the Scale of Dangerous and Threatening Worldview (alpha $=.87$ ) (Duckitt et al. 2002). Overall ANOVA revealed statistically significant differences between group means: 
$F(2 ; 147)=18.63, p<.001$. Post-hoc comparisons performed by the Scheffe test showed expected and significant differences between the threatening $(M=3.88, S D=.72)$ and secure $(M=2.99, S D=.78)$ scenario group: $t(98)=6.09, p<.001$, as well as between the threatening and neutral $(M=3.48$, $S D=.68)$ scenario group: $t(98)=2.7, p=.027$.

\section{Participants and Procedure}

Participants of the study 1 were recruited from the Nationwide Research Panel Ariadna, with about 100,000 registered consumers. The condition for them to join the panel is to give written consent for voluntary participation in various social and market research. The authors did not have access to any information identifying participant.

A total of 180 participants were recruited to participate in the study 1 . The approximate sample size was estimated for $\mathrm{F}$ tests in ANCOVA, and it was done using the $G^{*}$ Power 3.1 software with input parameters: effect size $\mathrm{f}=.25-.30$; $\alpha$ error probability $=.05$; a'priori Power $=.80$; number of groups $=3$.

The participants were $50 \%$ women and men. There were $16.7 \%$ of respondents in the 18 to 24 age bracket, 35.6 aged $25-34,32.2 \%$ aged $35-44$, and $15.4 \%$ aged $45-54$. The average age in the sample was $\mathrm{M}=34.5(\mathrm{Me}=33.5)$. Primary and lower education was held by $1.1 \%$ of respondents, vocational $-8.6 \%$, secondary and post-secondary $-46 \%$, and $44.3 \%$ of the respondents had higher education.

The research procedure was fully computerized. At the beginning, participants were informed they would take part in a study aiming to understand their attitudes and opinions on social life and politics. Then, all 180 participants filled out the Moral Foundations Questionnaire, which included items indexing four moral intuitions: Care/harm, Fairness/ reciprocity, Ingroup/loyalty, and Authority/respect (Graham et al. 2011). In the next step, participants were randomly assigned to three equal groups. Each group read a different scenario as described in the preliminary study. Finally, respondents were requested to fill out the scales of RWA and SDO (in random order).

\section{Measures}

Ethics of Autonomy and Ethics of Community The Moral Foundations Questionnaire (Graham et al. 2011) was used to measure four moral intuitions: Care/harm, Fairness/reciprocity, Ingroup/loyalty, and Authority/respect. Each of them included 6 items: three on the subscale of moral relevance (response options from $1=$ not at all relevant to $6=$ extremely relevant) and three on the subscale of moral judgments (response options from $1=$ strongly disagree to $6=$ strongly agree). Examples for moral relevance subscale: Care/Harm - 'Whether or not someone suffered emotionally'; Fairness/ reciprocity - Whether or not someone was denied his or her rights'; Ingroup/loyalty - 'Whether or not someone did something to betray his or her group '; Authority/respect: 'Whether or not someone showed a lack of respect for authority'. Examples for moral judgments subscale: Care/Harm 'Compassion for those who are suffering is the most crucial virtue'; Fairness/reciprocity - 'Justice is the most important requirement for a society'; Ingroup/loyalty - 'It is more important to be a team player than to express oneself'; Authority/ respect: 'Respect for authority is something all children need to learn'. The internal reliability for these four 6-item scales amounted to $\alpha=.78, .76, .68$ and .67 , respectively.

Right-wing Authoritarianism (RWA) and Social Dominance Orientation (SDO) RWA was measured by 12 items selected by Funke (2005) from Altemeyer's (1996) original instrument to measure RWA components separately: submission (4 items) - e.g. 'Obedience and respect for authority are the most important values children should learn'; aggression (4 items) e.g. 'What our country really needs instead of more 'civil rights' is a good stiff dose of law and order', and conventionalism (4 items) - e.g. 'Being virtuous and law-abiding is in the long run better for us than permanently challenging the foundation of our society'.

SDO was measured using the 12-item $\mathrm{SDO}_{5}$ scale developed by Sidanius and Pratto (1999) (two items, 3 and 7, from the original 14-item scale have been removed due to the low discriminant power). Examples: 'Some groups of people are simply not the equals of others', 'Some people are just more worthy than others', 'We should try to treat one another as equals as much as possible'.

Responses for RWA were coded on a scale from 1 (strongly disagree) to 7 (strongly agree), and for SDO from 1 (strongly disagree) to 6 (strongly agree). Internal reliability for RWA and SDO amounted to alpha $=.75$ and .74 , respectively.

\section{Study 2}

\section{Manipulation and Pilot Study}

In this study Group 1 was the control one. Participants in the remaining two groups read different scenarios. They were asked to imagine themselves in 10 years, running a mediumsized company engaged in providing short-term loans for less wealthy households. In Group 2 (Nonaggressive Competition), the company worked in rather friendly market conditions and was not forced to compete aggressively. At a meeting with their closest associates participant, as general manager, presented the good condition of the company, announced the rejection of aggressive competition, and proposed some prosocial projects to be undertaken by the company. In Group 3 (Aggressive Competition), the company worked in very unfavorable market conditions and was forced to compete aggressively. At a meeting with their closest 
associates, participants presented the difficult condition of the company and appealed for the intensification of aggressive market competition. The full text of group scenarios is provided in the supplementary materials.

The effectiveness of manipulation procedure was first checked in a pilot study on 150 volunteers randomly assigned to three equal groups. In groups 2 and 3, after reading the scenario, participants were asked to respond to a 15 -item balanced scale of Competitive Jungle Belief developed by Duckitt et al. $(2002)($ alpha $=.90)$. Overall ANOVA revealed statistically significant differences between group means: $F(2 ; 147)=10.7, p<.001$. Post-hoc comparisons performed by the Scheffe test showed that participants in the group with the Aggressive Competition scenario $(M=3.44, S D=.76)$ scored significantly higher on the Competitive Jungle scale than participants in the group with the Nonaggressive Competition scenario $(M=2.80, S D=.74), t(98)=4.3$, $p<.001$, and participants in the control group $(M=2.90$, $S D=.72), t(98)=3.6, p=.002$.

\section{Participants and Procedure}

A total of 150 participants were recruited to participate in the study 2 . There were $50.7 \%$ male and $49.3 \%$ female respondents. The approximate sample size was estimated using the $G^{*}$ Power 3.1 software in a similar way as described in Study 1. As in study 1 , participants were recruited from the Nationwide Research Panel Ariadna, with about 100,000 registered consumers. The sample included $16.6 \%$ of respondents in the 18 to 24 age bracket, $33.3 \%$ aged $25-34,32.1 \%$ aged $35-44$, and $18 \%$ aged $45-54$. The average age in the sample was $\mathrm{M}=35(\mathrm{Me}=34.5)$. Primary and lower education was held by $2 \%$ of respondents, vocational $-6.7 \%$, secondary and post-secondary $-46.7 \%$, and $44.6 \%$ of the respondents had higher education.

The research procedure was fully computerized and very similar to study 1 . At the beginning, participants were informed they would take part in a study aiming to understand their attitudes and opinions on social life and politics. Then, all 150 participants filled out the Moral Foundations Questionnaire. In the next step, participants were randomly assigned to three equal groups. The first group was control one. Participants in groups 2 and 3 read scenarios. Finally, participants were requested to fill out SDO and RWA scales (in random order).

\section{Measures}

Ethics of Autonomy and Ethics of Community As in study 1, the Moral Foundations Questionnaire (Graham et al. 2011) was used to measure four moral intuitions: Care/harm, Fairness/reciprocity, Ingroup/loyalty, and Authority/respect.
The internal reliability for these four scales amounted to $\alpha=.76, .74, .67$ and .69 , respectively.

Right-wing Authoritarianism As in study 1, RWA was measured by 12 items selected by Funke (2005) from Altemeyer's (1996) original instrument (internal reliability amounted to $\alpha=.85$ ).

Social Dominance Orientation As in study 1, SDO was measured using 12-item scale developed by Sidanius and Pratto (1999) (internal reliability amounted to $\alpha=.82$ ).

\section{Results}

\section{Study 1}

This study was aimed to confirm the hypothesis stating that the strongest positive relationships between the moral intuitions of the Ethics of Community and RWA should be observed when the social order is perceived as threatened.

Table 1 shows two strong relationships within a set of moral intuitions. These are correlations between Care/harm and Fairness/reciprocity, $r(174)=.45, p<001$, and between Ingroup/loyalty and Authority/respect, $r(174)=.50, p<001$. As argued earlier, both these pairs of moral intuitions can be seen as more general dimensions of Ethics of Autonomy and Ethics of Community, respectively (cf. Shweder et al. 1997). As expected, the moral intuitions forming Ethics of Autonomy were significantly negatively related to SDO: $r(174)=-.42, p<001$, for Care/harm, and $r(174)=-.43$, $p<001$, for Fairness/reciprocity. Also, as expected, the moral intuitions that make up the Ethics of Community were significantly positively related to RWA: $r(174)=.31, p<001$, for Ingroup/loyalty, and $r(174)=.41, \mathrm{p}<001$, for Authority/respect. Care/harm and Fairness/reciprocity turned out to be unrelated to SDO, while Ingroup/loyalty and Authority/ respect were unrelated to RWA.

Table 1 Correlations and descriptive statistics (Study 1)

$\begin{array}{lllll}\text { (1) } \quad \text { (2) (3) (4) (6) } & \text { (3) }\end{array}$

Care/Harm (1)

Fairness/reciprocity (2) $\quad .45^{* *}$

Ingroup/loyalty (3) $\quad-.09 \quad .22^{* *}$

Authority/respect (4) $\quad .02 \quad .09 \quad .50^{* *}$

$\begin{array}{lllll}\text { RWA (5) } & -.01 & .06 & .31^{* *} & .41^{* * *}\end{array}$

SDO (6) $\quad-.42^{* *} \quad-.43^{* *} \quad .02 \quad-.05 \quad 04$

$\begin{array}{lllllll}M & 5.01 & 4.40 & 3.79 & 3.81 & 4.01 & 3.10\end{array}$

$\begin{array}{llllllll}S D & .74 & .82 & .83 & .73 & .60 & .61\end{array}$

Notes. ${ }^{*} p \leq .05^{* *} p \leq .01$ 
After experimental manipulation mean values of RWA and SDO amounted to, respectively: neutral scenario group: $M=4.14(S D=.56)$ and $3.11(S D=.65)$; secure scenario group: $M=4.03(S D=.60)$ and $3.01(S D=.56)$; and threatening scenario group: $M=4.05(S D=.64)$ and 3.19 $(S D=.61)$. The mean values of RWA and SDO did not differ by the conditions, $F(2 ; 171)=0.5, p=.596$, and $F(2 ; 171)=$ $1.3, p=.284$, respectively.

The left part of Table 2 presents verification of the interaction hypothesis. Manipulation was included in the regression analysis by means of two dummy variables representing secure scenario group and threatening scenario group (the neutral scenario group was a reference one). The main interaction hypothesis predicted two interaction effects: Ingroup/loyalty $\mathrm{x}$ Social Threat on RWA and Authority/respect $x$ Social Threat on RWA. It means that the preference for these two moral intuitions should increase the level of RWA in the threatening scenario group.

In the overall model presented in Table 2 the difference in the level of RWA between neutral scenario group and social threat scenario group, which was non-significant in one-way
Anova, becomes significant at $p=0.05$, i.e. the condition of social threat turns out to be related to a slight decrease and not increase in the overall RWA. However, both hypothesized interactions - Ingroup/loyalty x Social Threat and Authority/ respect $\mathrm{x}$ Social Threat - proved to be statistically significant and going in expected direction: $F_{\text {change }}(1 ; 158)=5.37$, $p=.022$, and $F_{\text {change }}(1 ; 158)=4.19, p=.042$, respectively. Interaction Ingroup/loyalty x Social Threat brings a $2.5 \%$ contribution to $\mathrm{R}^{2}$, while the contribution of Authority/respect $\mathrm{x}$ Social Threat amounts to $2 \%$. In addition to these two, no other interaction effect was statistically significant.

Looking at the main effects of moral intuitions one can observe significant effect of Authority/respect. More importantly, the positive predictive effect of Authority/respect on RWA is definitely higher in the threatening scenario group than in the remaining groups. In the case of Ingroup/loyalty, its total effect on RWA is positive, but non-significant. However, the positive relationship between Ingroup/loyalty and RWA becomes strong and significant in the condition with social threat scenario. All in all, both moral intuitions forming the Ethics of Community predict right-wing
Table 2 Regression analysis of right-wing authoritarianism and social dominance orientation on moral intuitions, manipulation of social threat, and their two-way interactions (Study 1)

\begin{tabular}{|c|c|c|c|c|c|c|}
\hline & \multicolumn{3}{|c|}{$\begin{array}{l}\text { Right-wing Authoritarianism } \\
\text { (RWA) }\end{array}$} & \multicolumn{3}{|c|}{$\begin{array}{l}\text { Social Dominance Orientation } \\
\text { (SDO) }\end{array}$} \\
\hline & $\mathrm{B}$ & $p$ value & $95 \% \mathrm{CI}$ & $\mathrm{B}$ & $\mathrm{p}$ value & $95 \% \mathrm{CI}$ \\
\hline Constant & 2.55 & $<0.001$ & $(1.49 ; 3.61)$ & 4.85 & $<0.001$ & $(4.04 ; 5.66)$ \\
\hline \multicolumn{7}{|l|}{ Moral intuitions } \\
\hline Care/harm & -0.01 & 0.833 & $(-0.14 ; 0.12)$ & -0.19 & 0.003 & $(-0.31 ; 0.07)$ \\
\hline Fairness/reciprocity & 0.01 & 0.934 & $(-0.12 ; 0.13)$ & -0.27 & $<0.001$ & $(-0.39 ; 0.16)$ \\
\hline Ingroup/loyalty & 0.10 & 0.139 & $(-0.03 ; 0.21)$ & 0.10 & 0.087 & $(-0.02 ; 0.22)$ \\
\hline Authority/respect & 0.31 & $<0.001$ & $(0.18 ; 0.45)$ & 0.02 & 0.742 & $(-0.16 ; 0.12)$ \\
\hline \multicolumn{7}{|l|}{ Manipulation $^{\mathrm{a}}$} \\
\hline Secure (2) & 0.92 & 0.062 & $(-0.05 ; 1.92)$ & -0.45 & 0.365 & $(-1.42 ; 0.53)$ \\
\hline Threatening (3) & -1.13 & 0.039 & $(-2.20 ;-0.06)$ & -0.80 & 0.137 & $(-1.85 ; 0.26)$ \\
\hline \multicolumn{7}{|l|}{ Interaction effects } \\
\hline Care x Group 2 & -0.12 & 0.202 & $(-0.31 ; 0.07)$ & 0.11 & 0.227 & $(-0.07 ; 0.29)$ \\
\hline Care x Group 3 & 0.05 & 0.589 & $(-0.13 ; 0.24)$ & 0.15 & 0.106 & $(-0.03 ; 0.33)$ \\
\hline Fairness x Group 2 & 0.01 & 0.922 & $(-0.16 ; 0.17)$ & -0.05 & 0.529 & $(-0.22 ; 0.11)$ \\
\hline Fairness x Group 3 & -0.14 & 0.096 & $(-0.30 ; 0.02)$ & -0.05 & 0.519 & $(-0.21 ; 0.11)$ \\
\hline Ingroup x Group 2 & -0.03 & 0.726 & $(-0.20 ; 0.14)$ & -0.03 & 0.762 & $(-0.19 ; 0.14)$ \\
\hline Ingroup x Group 3 & 0.19 & 0.022 & $(0.03 ; 0.35)$ & 0.01 & 0.896 & $(-0.15 ; 0.17)$ \\
\hline Authority x Group 2 & -0.08 & 0.413 & $(-0.27 ; 0.11)$ & 0.05 & 0.605 & $(-0.14 ; 0.23)$ \\
\hline Authority x Group 3 & 0.20 & 0.042 & $(0.01 ; 0.38)$ & 0.09 & 0.338 & $(-0.10 ; 0.28)$ \\
\hline \multicolumn{7}{|l|}{ Covariates } \\
\hline RWA & & & & 0.02 & 0.784 & $(-0.13 ; 0.18)$ \\
\hline SDO & 0.02 & 0.784 & $(-0.14 ; 0.18)$ & & & \\
\hline$F_{(15 ; 158)}$ & \multicolumn{3}{|c|}{$4.21<0.001$} & \multicolumn{3}{|c|}{$5.26<0.001$} \\
\hline$R^{2}$ total & \multicolumn{3}{|c|}{0.29} & \multicolumn{3}{|c|}{0.33} \\
\hline
\end{tabular}

Notes. ${ }^{a}$ coding: (1) Neutral (0; 0); (2) Secure (1;0); (3) Threatening $(0 ; 1)$ 
authoritarianism with special strength when the social order is perceived as threatened. Graphical representations of both interactions are depicted in Figs. 1 and 2, respectively.

The right part of Table 2 contrasts the model for RWA with an identical model but containing SDO as a dependent variable. As one might expect, in this competitive model, we notice only two statistically significant negative predictors of SDO - Care/harm and Fairness/reciprocity. No interaction effect was found to be statistically significant.

\section{Summary}

Study 1 revealed substantial positive relationships between moral intuitions forming the Ethics of Community and RWA. The main goal of the study was to find out whether the strongest positive predictive effect of Ingroup/loyalty and Authority/respect on RWA appear in situation that incline the person to perceive the social order as threatened. Indeed, compared with the remaining groups, in the context of threat to social order the positive effect of moral intuitions concerning Ingroup/Loyalty and Authority/respect on RWA was definitely the most powerful. It suggests that even if the Ethics of Community seems overall to be a clear moral premise for the expression of RWA attitudes, its power is exceptionally strong in times of social disorder and disintegration.

Although the expected interactions were positive and statistically significant, manipulation of the social threat did not in itself cause an increase in RWA. It was possible because the induction of social threat caused the opposite effects among people with low and high Ethics of Community. The expected increase in RWA in people with high Ingroup/Loyalty and Authority/respect was accompanied by the decrease in RWA in people with low Ingroup/Loyalty and Authority/respect. This suggests that perceived social threat evokes not specific but general effect of consolidation of submissive authoritarianism and moral intuitions based on the Ethics of Community.

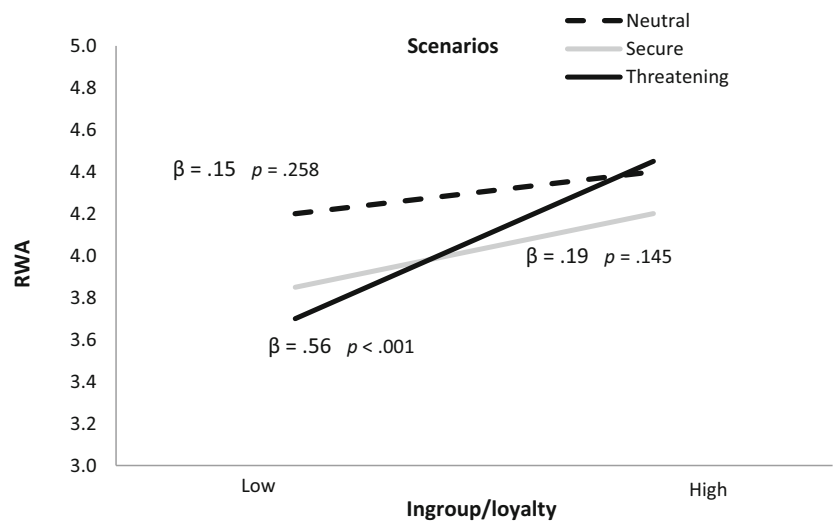

Fig. 1 Social threat moderating the effect of Ingroup/loyalty on rightwing authoritarianism (Study 1). $\beta$ - standardized simple slopes

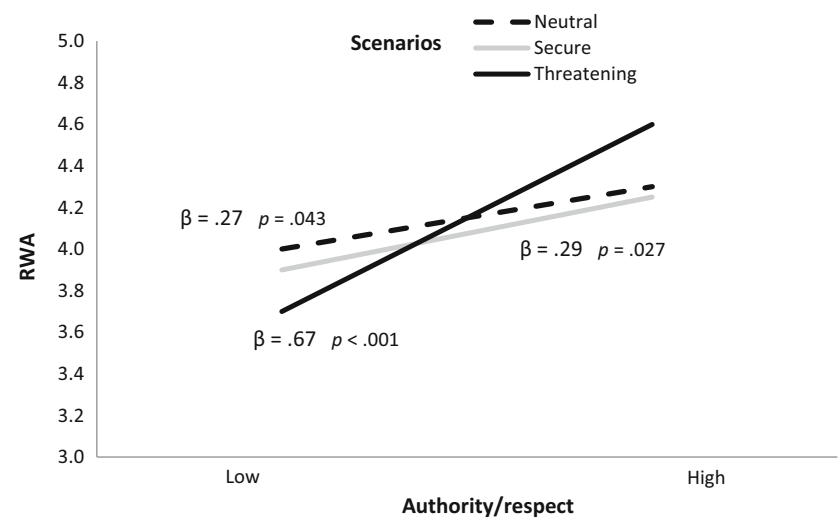

Fig. 2 Social threat moderating the effect of Authority/respect on rightwing authoritarianism (Study 1). $\beta$ - standardized simple slopes

The more someone values community moral intuitions, the more he/she approves RWA, and conversely.

\section{Study 2}

This study was aimed to confirm the hypothesis stating that the strongest negative relationship between the moral intuitions of the Ethics of Autonomy and SDO should be observed when the social environment is perceived as governed by the rules of aggressive and ruthless competition.

Table 3 shows, as in study 1 , strongest relationships between two pairs of moral intuitions: Care/harm - Fairness/reciprocity, $r(147)=.47, p<001$, and Ingroup/loyalty - Authority/respect, $r(147)=.53, p<001$. Similar to the previous study, Care/harm and Fairness/reciprocity were significantly negatively related to SDO: $r(147)=-.28, p<001$, and $r(147)=-.18, p<001$, respectively; while Ingroup/loyalty and Authority/respect were significantly positively related to RWA: $r(147)=.54, p<001$, and $r(147)=.48, p<001$, respectively.

After experimental manipulation mean values of SDO and RWA amounted to, respectively: control group: $M=2.99$ $(S D=.64)$ and $4.05(S D=.88)$; nonaggressive competition scenario group: $M=2.78(S D=.77)$ and $3.76(S D=.77)$;

Table 3 Correlations and descriptive statistics (Study 2)

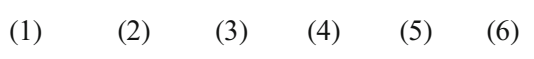

Care/Harm (1)

\begin{tabular}{llllllll} 
Fairness/reciprocity (2) & $.47^{* *}$ & & & & & \\
Ingroup/loyalty (3) & -.04 & $.36^{* *}$ & & & & \\
Authority/respect (4) & .07 & .06 & $.53^{* *}$ & & & \\
RWA (5) & .08 & $.26^{* *}$ & $.54^{* *}$ & $.48^{* *}$ & & \\
SDO (6) & $-.28^{* *}$ & $-.18^{*}$ & .01 & .09 & -.02 & \\
$M$ & 4.97 & 4.41 & 3.87 & 3.75 & 3.08 & 3.96 \\
$S D$ & .79 & .85 & .90 & .87 & .74 & .83 \\
\hline
\end{tabular}

Notes. ${ }^{*} p \leq .05^{* *} p \leq .01$ 
and aggressive competition scenario group: $M=3.47$ $(S D=.63)$ and $4.07(S D=.82)$. The mean values of RWA did not differ by the conditions, $F(2 ; 147)=2.27, p=.106$, while for mean values of SDO analysis of variance revealed significant difference between aggressive competition group and control group, $t(98)=3.79, p<.001$, as well as between aggressive competition group and nonaggressive competition group, $t(98)=4.91, p<.001$.

The left part of Table 4 presents verification of the interaction hypothesis. Manipulation was included in the regression analysis by means of two dummy variables representing nonaggressive competition scenario group and aggressive competition scenario group (the control group was a reference one). The main interaction hypothesis predicted two interaction effects: Care/harm x Aggressive Competition on SDO and Fairness/reciprocity $\mathrm{x}$ Aggressive Competition on SDO. According to hypotheses the preference for these two moral intuitions should decrease the level of SDO in the aggressive competition scenario group.
Both hypothesized interactions - Care/harm x Aggressive Competition and Fairness/reciprocity $x$ Aggressive Competition - proved to be statistically significant but unexpectedly going in the opposite direction: $F_{\text {change }}(1 ; 134)=$ $5.75, p=.018$, and $F_{\text {change }}(1 ; 134)=5.14, p=.025$, respectively. Interaction Care/harm x Aggressive Competition brings a $3 \%$ contribution to $\mathrm{R}^{2}$, while the contribution of Fairness/reciprocity $\mathrm{x}$ Aggressive Competition amounts to $2 \%$. In addition to these two, no other interaction effect was statistically significant.

Table 4 shows significant negative effects of Care/harm and Fairness/reciprocity. Unexpectedly, the condition with aggressive competition scenario, instead of sharpening negative relationships of Care/harm and Fairness/ reciprocity with SDO, results in their disappearance. When the social environment is perceived in terms of aggressive 'Darwinian' competition, the moral intuitions of the Ethics of Autonomy not only do not gain in importance but even lose their meaning as a moral premise to reject the
Table 4 Regression analysis of social dominance orientation and right-wing authoritarianism on moral intuitions, manipulation of competition, and their two-way interactions (Study 2)

\begin{tabular}{|c|c|c|c|c|c|c|}
\hline & \multicolumn{3}{|c|}{$\begin{array}{l}\text { Social Dominance Orientation } \\
\text { (SDO) }\end{array}$} & \multicolumn{3}{|c|}{$\begin{array}{l}\text { Right-wing Authoritarianism } \\
\text { (RWA) }\end{array}$} \\
\hline & $\mathrm{B}$ & $p$ value & $95 \% \mathrm{CI}$ & $\mathrm{B}$ & $\mathrm{p}$ value & $95 \% \mathrm{CI}$ \\
\hline Constant & 4.70 & $<0.001$ & $(3.87 ; 5.53)$ & 2.90 & $<0.001$ & $(1.73 ; 4.07)$ \\
\hline \multicolumn{7}{|l|}{ Moral intuitions } \\
\hline Care/harm & -0.25 & 0.036 & $(-0.56 ;-0.03)$ & -0.12 & 0.155 & $(-0.32 ; 0.05)$ \\
\hline Fairness/reciprocity & -0.32 & 0.024 & $(-0.62 ;-0.09)$ & -0.08 & $<0.360$ & $(-0.29 ; 0.10)$ \\
\hline Ingroup/loyalty & 0.03 & 0.784 & $(-0.16 ; 0.22)$ & 0.45 & $<0.001$ & $(0.26 ; 0.65)$ \\
\hline Authority/respect & 0.16 & 0.144 & $(-0.09 ; 0.45)$ & 0.24 & 0.010 & $(0.06 ; 0.42)$ \\
\hline \multicolumn{7}{|l|}{ Manipulation $^{\mathrm{a}}$} \\
\hline Nonaggressive (2) & 0.11 & 0.852 & $(-1.07 ; 1.30)$ & -0.50 & 0.450 & $(-1.80 ; 0.80)$ \\
\hline \multicolumn{6}{|l|}{$\begin{array}{l}\text { competition } \\
\text { Interaction effects }\end{array}$} & $(-1.29 ; 0.85)$ \\
\hline Care x Group 2 & -0.18 & 0.136 & $(-0.42 ; 0.06)$ & 0.12 & 0.375 & $(-0.15 ; 0.38)$ \\
\hline Care x Group 3 & 0.27 & 0.018 & $(0.05 ; 0.48)$ & -0.09 & 0.456 & $(-0.34 ; 0.15)$ \\
\hline Fairness x Group 2 & -0.14 & 0.280 & $(-0.39 ; 0.11)$ & -0.25 & 0.076 & $(-0.53 ; 0.03)$ \\
\hline Fairness x Group 3 & 0.26 & 0.025 & $(0.03 ; 0.50)$ & 0.24 & 0.072 & $(-0.02 ; 0.50)$ \\
\hline Ingroup x Group 2 & 0.15 & 0.234 & $(-0.10 ; 0.39)$ & 0.01 & 0.913 & $(-0.25 ; 0.28)$ \\
\hline Ingroup x Group 3 & -0.18 & 0.184 & $(-0.45 ; 0.09)$ & -0.01 & 0.970 & $(-0.30 ; 0.29)$ \\
\hline Authority x Group 2 & 0.14 & 0.220 & $(-0.08 ; 0.36)$ & 0.21 & 0.083 & $(-0.34 ; 0.19)$ \\
\hline Authority x Group 3 & -0.12 & 0.321 & $(-0.37 ; 0.12)$ & -0.08 & 0.580 & $(-0.37 ; 0.01)$ \\
\hline \multicolumn{7}{|l|}{ Covariates } \\
\hline RWA & -0.15 & 0.059 & $(-0.30 ; 0.01)$ & & & \\
\hline SDO & & & & -0.18 & 0.059 & $(-0.37 ; 0.01)$ \\
\hline$F_{(15 ; 134)}$ & \multicolumn{3}{|c|}{$5.15<0.001$} & \multicolumn{3}{|c|}{$5.77<0.001$} \\
\hline$R^{2}$ total & \multicolumn{3}{|c|}{0.37} & \multicolumn{3}{|c|}{0.39} \\
\hline
\end{tabular}

Notes. ${ }^{\text {a }}$ coding: (1) Control ( $\left.0 ; 0\right) ;(2)$ Nonaggressive competition (1; 0$) ;(3)$ Aggressive competition $(0 ; 1)$ 
SDO. Graphical representations of both interactions are depicted in Figs. 3 and 4, respectively.

The right part of Table 4 contrasts the model for SDO with an identical model but containing RWA as a dependent variable. Two variables, Ingroup/loyalty and Authority/respect, turned out to be statistically significant positive predictors of RWA. No interaction effect was found to be statistically significant.

\section{Summary}

Study 2, similarly to Study 1, revealed the substantial negative predictive effect of the Ethics of Autonomy on SDO. The main goal of the study was to find out whether the negative effects of Care/harm and Fairness/reciprocity increase when the social environment is perceived as governed by the rules of "competitive jungle". Unlike expected, the relationships of moral intuitions forming the Ethics of Autonomy turned out not the strongest but the weakest (and even non-significant) in the experimental condition of aggressive competition. Thus, when the social environment is perceived as governed by the rules of 'Darwinian' competition, people with a high level of concern for well-being and justice for other people (high Ethics of Autonomy) express quite similar high SDO as those who are low on the Ethics of Autonomy. Manipulation of the competitive threat resulted in a statistically significant increase in SDO in aggressive competition scenario group compared to nonaggressive competition scenario group. However, as shown in Figs. 3 and 4, this has not happened because of the increase in SDO among people with low Ethics of Autonomy but on account of a clear increase in SDO among people with high Ethics of Autonomy.

\section{Discussion}

Numerous studies indicate authoritarianism as something that particularly strongly undermine pro-democratic values (e.g.

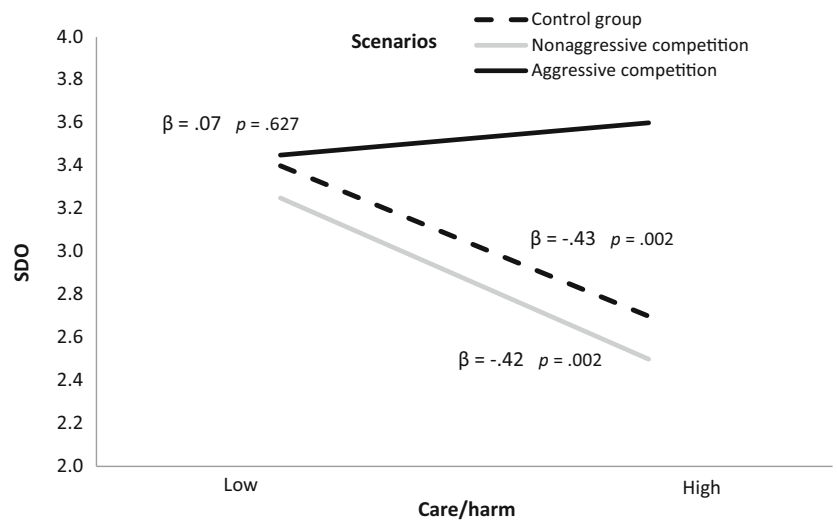

Fig. 3 Aggressive competition moderating the effect of Care/harm on social dominance orientation (Study 2). $\beta$ - standardized simple slopes

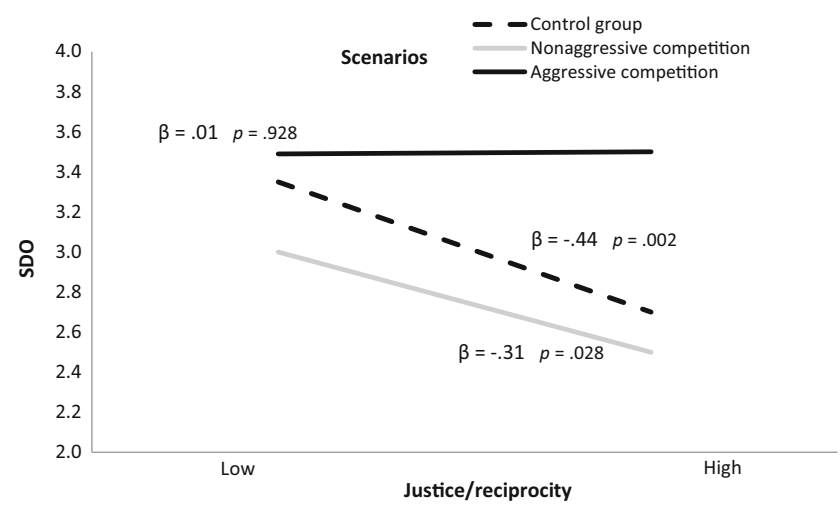

Fig. 4 Aggressive competition moderating the effect of Fairness/ reciprocity on social dominance orientation (Study 2 ). $\beta$ - standardized simple slopes

Altemeyer 2004; McFarland 2010; Duckitt and Sibley 2010). This kind of attitudes/ideologies attract the attention of many researchers, because, especially in their most radical forms, they express such a vision of a society and social order which is fundamentally contrary to the basic principles of modern liberal democracy. Many years of research, initiated by the famous work of 'The Authoritarian personality' by Adorno et al. (1950), point out that authoritarianism can be seen as a complex mental phenomenon consisting of two broad and relatively independent components. According to the Dual Process Motivational (DPM) model (Duckitt 2001; Duckitt and Sibley 2010), the dual nature of authoritarianism is best reflected by RWA ('submissive' authoritarianism) and SDO ('dominative' authoritarianism). A high level of RWA is in collision with the values of freedom, human rights and tolerance, whereas a high level of SDO works against the principles of equality and social solidarity. The sets of ideological beliefs contained in RWA and SDO, which can be categorized respectively as anti-liberal and anti-egalitarian attitudes, are of particular interest in social and political psychology for decades.

Though moral preferences seem to be the natural and most basic motivation for building a coherent ideological vision of the social order contained in authoritarianism, this issue has not attracted researchers' interest for many years. The previous research underestimated or even marginalized this domain of human motivation. In the dominant approach, which defined the moral domain as matter of 'justice, rights, and welfare' (Gilligan 1982), SDO and RWA have been seen as symptoms of moral deficits. Norms and values other than justice, human rights or welfare were rather recognized as matters of social convention (Turiel 1983). In recent years, on the basis of Moral Foundations Theory, a number of empirical evidence linking morality and authoritarianism has appeared. These findings suggested: 1) substantial positive relationships between RWA and ethical codes oriented to protection of groups/communities (the Ethics of Community); 2) substantial negative relationships between SDO and ethical 
codes oriented to protection of individual (the Ethics of Autonomy) (Graham et al. 2009; Kugler et al. 2014). This was confirmed in both studies presented in this paper - high Ethics of Community predicted high RWA, while high Ethics of Autonomy predicted low SDO.

In direct proportion to its rise in publicity, the descriptivenaturalistic view on morality was criticized from various positions. For example, Suhler and Churchland (2011) strongly denied the claims about the innate nature of modular foundations, and Schein and Gray (2015) showed that moral foundations underlying liberalism and conservatism seemed to be not so different as suggested by MFT. However, this approach to morality seems to provide an important contribution to the field of research on authoritarianism. It emphasizes that in principle all human communities and societies face the dilemma of how to reconcile the rights and personal aspirations of the individuals with the cohesion and welfare of the whole community. Both the Ethics of Autonomy and the Ethics of Community can be regarded as functional and culturally universal codes of ethics on which the social order is being built. While we can observe clear geographical and cultural differences in promoting EA or $\mathrm{EC}$, there is no doubt that both can be identified everywhere. This primary duality of human ethics, expressing focus on protecting an individual or a community, clearly corresponds with the duality of authoritarian ideology as proposed by Duckitt (2001) in the Dual-Process Motivational model. Thus, in light of the presented studies (and several previous studies) the dualism of authoritarian ideology, expressed in RWA and SDO, results from the reason that has not been assumed in the DPM model. That reason is basic dualism of moral intuitions.

We think that it is reasonable to expect moral intuitions and authoritarian ideology to affect each other bidirectionally. This means that, on the one hand, we can talk about embeddedness of authoritarianism in moral intuitions (morality is the reason for expressing certain ideological content), and on the other hand, authoritarian ideology can reinforce certain moral intuitions (a product of justifying one's own attitudes or behavior arising from the ideological content). In view of the potential social consequences, we believe that the first path requires a lot more attention. Not moral intuitions but authoritarian ideology is a powerful predictor of a whole range of anti-democratic attitudes and behavior.

Focused on moral foundations of authoritarian ideology, we wanted to know whether relationships linking morality and authoritarianism would change or remain stable in times characterized by increased sense of danger and uncertainty. Previous research on RWA (e.g. Altemeyer 1988; Asbrock and Fritsche 2013; Fisher et al. 2010) and SDO (Morrison and Ybarra 2008; de Oliveira et al. 2012) suggested two primary moderators of such relationships - social and competitive threat, respectively. In our research, threat to social order was expected to be the social context which considerably strengthens the positive predictive effect of the Ethics of Community on RWA, while aggressive competition was expected to strengthen the negative predictive effect of the Ethics of Autonomy on SDO. The first moderation hypotheses found strong support in study 1 , which showed that perception of social order as breaking down might lead to stronger than ever 'moralization' of right-wing authoritarian ideology based on Ingroup/loyalty and Authority/respect moral standards. In study 2, the effect of Ethics of Autonomy on SDO diminished when social environment was perceived as governed by the rules of 'social jungle'. This effect was opposite to the expected one, because people with a high level of EA scored the highest on SDO in aggressive competition situation.

The results of study 1 suggest that in times of chaos and disintegration of the society the virtues forming Ethics of Community promote stable social order, internal harmony and cohesion - so everything what is crucial in RWA ideology. This means that when people perceive social chaos and disintegration around them, and they are high on the Ethics of Community, RWA ideology is attractive way to restore social order and personal safety. At the same time, people who were low on EC stronger rejected RWA. Therefore, even if the experience of social threat does not induce a noticeable increase in authoritarianism, the nature of RWA ideology can considerably change, because authoritarianism becomes an instrument of moral 'struggle between good and evil'. However, such a phenomenon of moralizing authoritarian ideology seems to occur only at the junction of the Ethics of Community and submissive authoritarianism (RWA). Study 2 suggests that in the conditions of growing competitive threat, the Ethics of Autonomy seems to be less and less related to the rejection of power, dominance and social hierarchy ideology. The inhibitory effect of EA on SDO can be partly or even fully suppressed by ruthless, aggressive competition for resources. People who highly value moral intuitions of Care/harm and Fairness/reciprocity begin to score relatively high on SDO. It could mean that in the social context of competitive threat, ideology contained in SDO loses its moral negativity (as something unacceptable on the basis of EA) and primarily become an adaptive strategy of personal survival.

The presented studies show that extending research on relationships between morality and authoritarianism by two aspects of the situational dynamics - threat to social order and competitive threat - brings a new and interesting contribution to the field. Our research suggest that, as a result of experiencing danger and uncertainty, tendency to authoritarian thinking and behavior may undergo strong moralization. Something like that happens between moral intuitions of the Ethics of Community and submissive authoritarianism (RWA). We suppose that in conditions of social threat, RWA ideology offers especially attractive way to restore social order and personal safety for people who highly value moral intuitions of Ingroup/loyalty 
and Authority/respect. It also seems to be consistent with the Terror Management Theory (TMT) (Greenberg et al. 1997), which predicts that in a situation of strong existential anxiety, people tend to concentrate on worldview orientations, important life values, moral standards, etc. Perception of threat and uncertainty reinforces the links between morality and RWA ideology, and make them more coherent. Social and political circumstances, like threat to social order, when RWA ideology becomes much more contingent on the relevant moral intuitions of the Ethics of Community may result in a strong polarization of the society and significantly increase the risk of sociopolitical conflict. This is because RWA carries a very strong anti-democratic and anti-liberal ideological content. The growing attractiveness of such ideology inevitably warm up emotions and exacerbate attitudes of those people who do not appreciate the moral value of Ingroup/loyalty or Authority/respect too much, but rather appreciate the values and standards of liberal democracy.

On the other hand, in the case of relationships between the Ethics of Autonomy and dominative authoritarianism (SDO), our research suggests a mechanism completely opposite to moralization. Although moral intuitions of Care/harm and Fairness/reciprocity seem to work like inhibitors of social dominance orientation, they stop working when social environment is perceived as governed by the rules of aggressive and ruthless competition. We suppose that in conditions of strong competitive threat, in people who highly value moral intuitions of Care/harm and Fairness/reciprocity disapproval of SDO ideology loses its moral justification. In other words, virtues such as care for others, justice, and reciprocity begin to be perceived as non-adaptive and limiting probability of personal or collective success. Such a highly traumatic social context - even if only imagined - appears to favor something that many researchers specify as the feeling of anomie. This state of mind means that under the pressure of hostile social conditions someone feels morally and emotionally lost (McClosky and Schaar 1965). Primarily, the growing sense of anomie results in a permanent increase in materialism, extreme individualism, depreciating the need for social solidarity. Typically, it is accompanied by indifference and withdrawal from the sphere of public affairs, lack of interest in politics, and escape into privacy. However, under favorable circumstances, an aversive state of anomic disorientation can quickly turn into passionate support for socio-political ideologies, usually offering as easy and simple as anti-democratic recipes (RWA ideology is a good example of this).

Finally, it is also worth admitting that the presented studies have several limitations and needs further development. Among other issues, the conceptual replication of the main findings (primarily use of alternative forms of manipulation with social threat and competitive threat) and proving the ecological validity of the results seem particularly urgent. Future work should also take into consideration potential cognitive mediators responsible for the moderation effects exerted by situational factors on RWA and SDO. Nevertheless, we believe that the research and conclusions presented in this paper can be considered as opening an interesting research perspective.

Funding This study was funded by the Polish National Science Center (NCN) grant UMO-2016/21/B/HS6/03213.

\section{Compliance with Ethical Standards}

Conflict of Interest The authors declare that they have no conflict of interest.

Ethics Approval Approval was obtained from the ethics committee of Institute of Psychology, Polish Academy of Sciences. The procedures used in these studies adhere to the tenets of Declaration of Helsinki.

Informed Consent Consent was obtained from all individual participants included in the studies. There is no identifying information included in this article.

Open Access This article is licensed under a Creative Commons Attribution 4.0 International License, which permits use, sharing, adaptation, distribution and reproduction in any medium or format, as long as you give appropriate credit to the original author(s) and the source, provide a link to the Creative Commons licence, and indicate if changes were made. The images or other third party material in this article are included in the article's Creative Commons licence, unless indicated otherwise in a credit line to the material. If material is not included in the article's Creative Commons licence and your intended use is not permitted by statutory regulation or exceeds the permitted use, you will need to obtain permission directly from the copyright holder. To view a copy of this licence, visit http://creativecommons.org/licenses/by/4.0/.

\section{References}

Adorno, T., Frenkel-Brunswik, E., Levinson, D., \& Sanford, N. (1950). The authoritarian personality. New York: Harper.

Altemeyer, R. (1981). Right-wing authoritarianism. University of Manitoba Press.

Altemeyer, R. (1988). Enemies of freedom: Understanding of right-wing authoritarianism. San Francisco: Jossey-Bass.

Altemeyer, R. (1996). The authoritarian specter. Harvard University Press.

Altemeyer, R. (2004). Highly dominating, highly authoritarian personalities. Journal of Social Psychology, 144, 421-447.

Asbrock, F., \& Fritsche, I. (2013). Authoritarian reactions to terrorist threat: Who is being threatened, the me or the we? International Journal of Psychology, 48(1), 35-49.

Ashton, M. C., Danso, H. A., Maio, G. R., Esses, V. M., Bond, M. H., \& Keung, D. K. Y. (2005). Two dimensions of political attitudes and their individual difference correlates: A cross-cultural perspective. In R. M. Sorrentino, D. Cohen, J. M. Olson, \& M. P. Zanna (Eds.), Culture and social behavior: The Ontario symposium (pp. 1-29). New York: Erlbaum.

Bell, D. (1996). The cultural contradictions of capitalism. New York: Basic Books.

de Oliveira, P., Guimond, S., \& Dambrun, M. (2012). Power and legitimizing ideologies in hierarchy-enhancing vs. hierarchy-attenuating environments. Political Psychology, 33(6), 839-865. 
Duckitt, J. (2001). A dual-process cognitive-motivational theory of ideology and prejudice. Advances in Experimental Social Psychology, $33,41-113$

Duckitt, J., \& Fisher, K. (2003). Social threat, worldview, and ideological attitudes. Political Psychology, 24, 199-222.

Duckitt, J., \& Sibley, C. G. (2010). Personality, ideology, prejudice, and politics: A dual-process process motivational model. Journal of Personality, 78, 1861-1894.

Duckitt, J., \& Sibley, C. G. (2016). The dual process motivational model of ideology and prejudice. In C. G. Sibley \& F. K. Barlow (Eds.), The Cambridge Handbook of the Psychology of Prejudice (pp. 188221). Cambridge: Cambridge University Press.

Duckitt, J., Birum, I., Wagner, C., \& du Plessis, I. (2002). The psychological bases of ideology and prejudice: Testing a dual process model. Journal of Personality and Social Psychology, 83, 75-93.

Duriez, B., Van Hiel, A., \& Kossowska, M. (2005). Authoritarianism and social dominance in Western and Eastern Europe: The importance of the sociopolitical context and of political interest and involvement. Political Psychology, 26, 299-320.

Fisher, P., Fisher, J., Frey, D., Such, M., Smyth, M., Tester, M., \& Kastenmüller, A. (2010). Causal evidence that terrorism salience increases authoritarian parenting practices. Social Psychology, 41(4), 246-254.

Fukuyama, F. (2018). Identity. The demand for dignity and the politics of resentment. New York: Ferrar, Sraus and Giroux.

Funke, F. (2005). The dimensionality of right-wing authoritarianism: Lessons from the dilemma between theory and measurement. Political Psychology, 26(2), 195-218.

Gilligan, C. (1982). In a different voice: Psychological theory and women's development. Cambridge: Harvard University Press.

Graham, J., Haidt, J., \& Nosek, B. (2009). Liberals and conservatives use different sets of moral foundations. Journal of Personality and Social Psychology, 96, 1029-1046.

Graham, J., Nosek, B. A., Haidt, J., Iyer, R., Koleva, S., \& Ditto, P. H. (2011). Mapping the moral domain. Journal of Personality and Social Psychology, 101, 366-385.

Greenberg, J., Solomon, S., \& Pyszczynski, T. (1997). Terror management theory of self-esteem and cultural worldviews: Empirical assessments and conceptual refinements. In M. P. Zanna (Ed.), Advances in experimental social psychology (Vol. 29, pp. 61-72). New York: Academic Press.

Haidt, J., \& Joseph, C. (2007). The moral mind: How 5 sets of innate intuitions guide the development of many culture-specific virtues, and perhaps even modules. In P. Carruthers, S. Laurence, \& S. Stich (Eds.), The innate mind (Vol. 3, pp. 367-391). New York: Oxford University Press.

Jost, J. T., Glaser, J., Kruglansky, A. W., \& Sulloway, F. J. (2003). Political conservatism as motivated social cognition. Psychological Bulletin, 129(3), 339-375.

Jugert, P., \& Duckitt, J. (2009). A motivational model of authoritarianism: Integrating personal and situational determinants. Political Psychology, 30(5), 693-719.

Kohlberg, L. (1969). Stage and sequence: The cognitive-developmental approach to socialization. In D. A. Goslin (Ed.), Handbook of socialization theory and research (pp. 347-480). Chicago: Rand McNally.

Kreuden-Sonnen, C. (2018). An authoritarian turn in Europe and European studies? Journal of European Public Policy, 25(3), 452464.

Kugler, M., Jost, J. T., \& Noorbaloochi, S. (2014). Another look at moral foundations theory: Do authoritarianism and social dominance orientation explain liberal-conservative differences in "moral" intuitions? Social Justice Research, 27, 413-431.

McClosky, H., \& Schaar, J. H. (1965). Psychological dimensions of anomy. American Sociological Review, 30(1), 14-40.

McFarland, S. (2010). Authoritarianism, social dominance and other roots of generalized prejudice. Political Psychology, 31, 425-449.

Morrison, K. R., \& Ybarra, O. (2008). The effects of realistic threat and group identification on social dominance orientation. Journal of Experimental Social Psychology, 44(1), 156-163.

Pratto, F., Sidanius, J., Stallworth, L. M., \& Malle, B. F. (1994). Social dominance orientation: A personality variable predicting social and political attitudes. Journal of Personality and Social Psychology, 67, 741-763.

Radkiewicz, P. (2016). Another look at the duality of the dual-process motivational model. On the role of axiological and moral origins of right-wing authoritarianism and social dominance orientation. Personality and Individual Differences, 99, 106-112.

Saucier, G. (2000). Isms and the structure of social attitudes. Journal of Personality and Social Psychology, 78, 366-385.

Schein, C., \& Gray, K. (2015). The unifying moral dyad: Liberals and conservatives share the same harm-based moral template. Personality and Social Psychology Bulletin, 41(8), 1147-1163.

Schwartz, S. (1994). Cultural dimensions of values: Toward an understanding of national differences. In U. Kim, H. Triandis, C. Kagitcibasi, S. Choi, \& G. Yooon (Eds.), Individualism and collectivism. Theory, method and application (pp. 58-78). New York: Sage.

Shweder, R. A., Much, N. C., Mahapatra, M., \& Park, L. (1997). The 'big three' of morality (autonomy, community and divinity), and the 'big three' explanations of suffering. In A. Brandt \& P. Rozin (Eds.), Morality and health (pp. 119-169). New York: Routledge.

Sidanius, J., Pratto, F. (1999). Social Dominance: An Intergroup Theory of Social Hierarchy and Oppression. Cambridge University Press.

Standard Eurobarometer 88. Autumn 2017 (2017). Public opinion in the European Union, http://www.poci-compete2020.pt/admin/images/ Standard_Eurobarometer_88_UE.

Stellmacher, J., \& Petzel, T. (2005). Authoritarianism as a group phenomenon. Political Psychology, 26, 245-274.

Suhler, C. L., \& Churchland, P. (2011). Can innate, modular "foundations" explain morality? Challenges for Haidt s moral foundations theory. Journal of Cognitive Neuroscience, 23, 2103-2116.

Turiel, E. (1983). The development of social knowledge: Morality and convention. Cambridge University Press.

Publisher's note Springer Nature remains neutral with regard to jurisdictional claims in published maps and institutional affiliations. 